\title{
Liquid chromatography-electro spray ionization tandem mass spectrometry for simultaneous determination of Moexipril and its active metabolite Moexiprilat in human plasma
}

\author{
Omar Abd Elaziz a, Maha Farouk a, Shereen Tawakkol b, Ahmed Hemdan c,* and Mostafa Shehata d \\ a Pharmaceutical Analytical Chemistry Department, Faculty of Pharmacy, Ain Shams University, Cairo, 11566, Egypt \\ b Pharmaceutical Analytical Chemistry Department, Faculty of Pharmacy, Helwan University, Cairo, 11431, Egypt \\ c Pharmaceutical Analytical Chemistry Department, Faculty of Pharmacy, Ahram Canadian University, 6th of October, 12566, Egypt \\ d Pharmaceutical Analytical Chemistry Department, Faculty of Pharmacy, Cairo University, Cairo, 12316, Egypt \\ *Corresponding author at: Pharmaceutical Analytical Chemistry Department, Faculty of Pharmacy, Ahram Canadian University, 6th of October, 12566, Egypt. \\ Tel.: +2.012.21620730. Fax: +2.023.8334379. E-mail address: hemmdan@yahoo.com (A. Hemdan).
}

\section{ARTICLE INFORMATION}

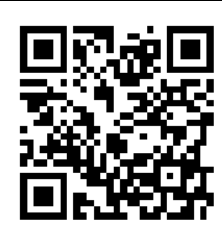

DOI: $10.5155 /$ eurjchem.5.4.662-667.1090

Received: 09 May 2014

Received in revised form: 04 July 2014

Accepted: 24 August 2014

Online: 31 December 2014

\section{KEYWORDS}

Plasma

Moexipril

LC-MS/MS

Benazepril

Moexiprilat

Simple protein precipitation

\section{Introduction}

Moexipril (3S)-2-[(2S)-2-[[(1S)-1-(ethoxycarbonyl)-3phenylpropyl]amino]-1-oxopropyl]-1, 2, 3, 4-tetrahydro-6, 7dimethoxy-3-isoquinolinecarboxylic acid [1] is an antihypertensive drug, which belongs to the group of angiotensin convertase inhibitors. Moexipril hydrochloride is a long-acting nonsulfhydryl angiotensin-converting enzyme (ACE) inhibitor, developed for the treatment of hypertension and congestive heart failure. Moexipril is a pro-drug of moexiprilat, which inhibits ACE in humans and animals. In biological systems it is rapidly de-esterified by esterases, resulting in its active metabolite moexiprilat $[2,3]$.

It is reported that MOX was identified by HPLC [4-6], spectrophotometry $[7,8]$, gas chromatography mass spectrometry [9], and liquid chromatography tandem mass spectrometry $[10,11]$. In 2006, Koti, J. et al. developed a LC-MASS spectrometry method just to monitor the metabolism of MOX to MOXT [10]. Also, in 2012, Karra et al. developed a method for determination of MOX by LC-Tandem mass spectrometry. But MOXT, which is the active metabolite was not determined [11].
MOX is only a pro-drug, which is converted inside the body to MOXT, the active form.

There is no report of liquid chromatography-tandem mass spectrometry studies for simultaneous estimation of MOX and its active metabolite MOXT in human plasma.

This manuscript presents for the first time the development and validation of a sensitive, selective and specific LCMS/MS method in multiple reactions monitoring (MRM) mode for the quantification of MOX and MOXT in human plasma using Benazepril (BENZ) as an internal standard (IS).

\section{Experimental}

\subsection{Materials and reagents}

MOX and BENZ were kindly supplied from National Organization for Drug Control and Research (NODCAR, Cairo, Egypt). The purity of the standards was higher than $99 \%$. Where MOXT was prepared by the basic hydrolysis of MOX as will be explained in section 2.5.1. Structures of the compounds are shown in Figure 1. 


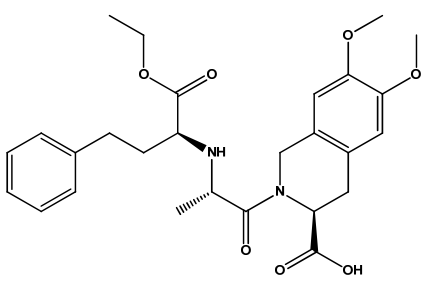

(a)

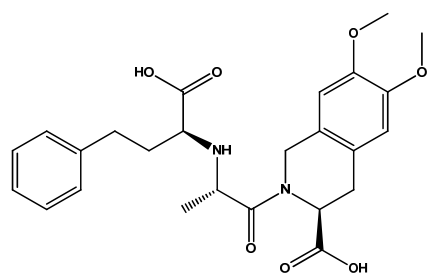

(b)

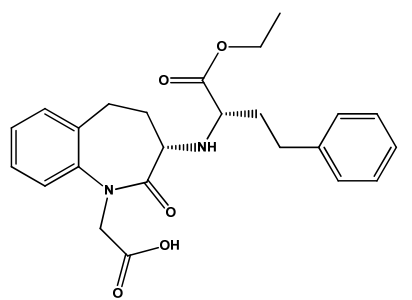

(c)

Figure 1. Chemical Structure of (a) Moexipril, (b) Moexiprilat, and (c) Benazepril.

HPLC-grade acetonitrile (Sigma-Aldrich), and ultrapure water prepared by a Millipore Milli- $Q$ purification system (Millipore Corp. Bedford, MA, USA) were used as mobile phase of the HPLC-MS-MS. Other reagents were of analytical-grade. Drug-free human plasma was obtained from The Holding Company for Biological Products \& Vaccines (VACSERA, Cairo, Egypt). Plasma was stored below $-40{ }^{\circ} \mathrm{C}$ until used for analysis.

\subsection{Instruments}

Analysis was performed on a chromatographic system Shimadzu LC-20 AT Series HPLC system (Japan) equipped with LC-20 AT HPLC pump, Shimadzu series DGU-20A5 Degasser and a Shimadzu SIL-20A auto sampler. A chromatographic separation was achieved by a Sunfire C18 column $(50 \times 4.6 \mathrm{~mm}$, $5 \mu \mathrm{m}$, Waters, USA) and a mixture of $0.1 \%$ formic acid: acetonitrile $(30: 70, v: v)$ as a mobile phase. The isocratic mobile phase, was filtered through a $0.45 \mu \mathrm{m}$ membrane filter (Millipore, USA), then sent to sonicator for $5 \mathrm{~min}$. The flow rate used was $0.8 \mathrm{~mL} / \mathrm{min}$.

The Multiple Reaction Monitoring (MRM) in positive ion mode was used for quantitative determination of the analytes and IS using a MDS Sciex (Foster City, CA, USA) API-3200 LCMS/MS triple quadrupole mass spectrometer, equipped with a Turbo ion spray interface at $350^{\circ} \mathrm{C}$. The common parameters, collision activated dissociation gas (CAD), nebulizer gas (GS1), and heater gas (GS2) were set at 5, 30 and 40 psi, respectively. The compound parameters, collision exit potential (CXP), collision energy (CE), and declustering potential (DP) for the analytes and IS were set at 12,31 , and $56 \mathrm{~V}$, respectively. Simultaneous quantitative determination of MOX, MOXT, and IS was done by monitoring the parent/daughter ions at $\mathrm{m} / \mathrm{z}$ 499.4/234.2, 471/206, and 425.2/351.2, respectively. Data acquisition was made with Analyst software (version 1.4.2).

\subsection{Preparation of standard solutions, calibration standards and quality control samples}

Standard solutions of MOX, MOXT, and internal standard (1 $\mathrm{mg} / \mathrm{mL}$ ) were prepared in acetonitrile. Further dilution was done for the preparation of standard working solution of MOX, MOXT, and internal standard $(1 \mu \mathrm{g} / \mathrm{mL})$. The standard working solutions were stored at $4{ }^{\circ} \mathrm{C}$ until used for analysis, where they were equilibrated to room temperature. Different aliquots from the standard working solutions were used for spiking blank human plasma to prepare calibration standards and quality control samples. Six different concentrations of MOX (0.5-100 $\mathrm{ng} / \mathrm{mL})$ and MOXT $(5-200 \mathrm{ng} / \mathrm{mL})$ were used as the calibration samples. Quality control samples used were: 0.5 (LLOQ), 15 (LQC), 50 (MQC), $100 \mathrm{ng} / \mathrm{mL}$ (HQC) for MOX, and 5 (LLOQ), 30 (LQC), 100 (MQC), $200 \mathrm{ng} / \mathrm{mL}$ (HQC) for MOXT.

\subsection{Simple protein precipitation}

A simple protein precipitation was done for extracting MOX, its active metabolite MOXT, and BENZ (IS) from human plasma. BENZ (IS) solution ( $25 \mu \mathrm{L}$ of $1000 \mathrm{ng} / \mathrm{mL}$ ) was added to $500 \mu \mathrm{L}$ plasma. Acetonitrile $(3 \mathrm{~mL})$ was added to precipitate plasma proteins, and then the samples were vortexed for $1 \mathrm{~min}$. The Centrifugation was done at $10,000 \mathrm{rpm}$ for $10 \mathrm{~min}$. The clear supernatant was transferred to a dry test tube and evaporated to dryness under a gentle stream of nitrogen gas at $40{ }^{\circ} \mathrm{C}$, and then the residue was reconstituted with $100 \mu \mathrm{L}$ of the mobile phase, where only $25 \mu \mathrm{L}$ was injected for the LCtandem mass analysis.

\subsection{Procedures}

\subsubsection{Stability of MOX}

MOX was subjected to basic degradation. Standard MOX powder $(100 \mathrm{mg})$ was weighed transferred to a conical flask. Then, $0.1 \mathrm{~N} \mathrm{NaOH}$ was added on the volumetric flask. Then the flask was refluxed for 0.5 hour. After the reflux, the conical flask was neutralized against $0.1 \mathrm{~N} \mathrm{HCl}$, then completed to $100 \mathrm{~mL}$ by distilled water. The complete degradation was confirmed using HPLC and mass spectrometry.

\subsubsection{For bulk powder}

Aliquot volumes from the standard working solutions of MOX and MOXT were accurately transferred to $10 \mathrm{~mL}$ volumetric flasks to which $500 \mu \mathrm{L}$ of IS was added to provide final concentrations of $0.5-100 \mathrm{ng} / \mathrm{mL}$ for MOX, and 5-200 ng/mL for MOXT. The volume was completed to the volume by the mobile phase. $25 \mu \mathrm{L}$ of each concentration was injected three times and following the chromatographic conditions.

\subsubsection{For extraction from human plasma}

Aliquot volumes from the standard working solutions of MOX and MOXT were added on $500 \mu \mathrm{L}$ human plasma, then 25 $\mu \mathrm{L}$ IS was added on each concentration. Then, $3 \mathrm{~mL}$ of acetonitrile was added, the samples were mixed on a vortex for 1 min, followed by centrifugation for $10 \mathrm{~min}$ at $10,000 \mathrm{rpm}$. The clear supernatant was transferred to a clean tube and evaporated to dryness under a gentle stream of nitrogen gas at $40{ }^{\circ} \mathrm{C}$. The residue was reconstituted with $100 \mu \mathrm{L}$ mobile phase, and $25 \mu \mathrm{L}$ was injected for LC-tandem mass analysis.

\subsection{Method validation}

The validation of the proposed method was done as per the FDA guidelines.

\subsubsection{Selectivity}

Blank human plasma from six different sources were tested for any interference of endogenous plasma constituents with the analytes and the IS. 


\subsubsection{Matrix effect}

It is the effect of the matrix which contains the analysed sample on the sample determination. To test for the effect of the studied matrix on the quantitative determination of the analytes, extraction was done to blank human plasma samples as explained earlier, and after the extraction step, the samples were spiked with three different quality control levels with the IS in triplicates. Then the samples were sent for analysis to obtain the peak areas. The peak areas obtained were compared with those obtained from standard solutions, where matrix effect is the peak area ratio. Matrix effect is usually done to ensure the precision and repeatability of the method.

\subsubsection{Recovery}

Calculation of the recovery \% is done to test for the extraction efficiency of the method. The extraction procedure was done as mentioned above for the spiked plasma samples and the peak areas were calculated. Then the peak areas of samples spiked after the extraction step was calculated. The ratio of the two peaks was the recovery \%. This was done at three quality control levels in triplicates.

\subsubsection{Calibration curves}

Samples used for calibration consist of six concentrations of MOX (0.5-100 ng/mL) and MOXT (5-200 ng/mL). Each concentration was injected three times. The relative peak area of each analyte was recorded against its concentration, the linearity curves were constructed and the regression equations computed.

\subsubsection{Precision and accuracy}

Three different QC levels of each analyte were analysed three times intra-daily using the proposed methods under the same experimental conditions to estimate precision and accuracy. The previous procedures were repeated inter-daily on three different days for the analysis of the three chosen concentrations to calculate the inter-assay precision. The relative standard deviations were calculated. The criteria for acceptability of data were accuracy within $\pm 15 \%$ from the nominal values and a precision of within $\pm 15 \%$ relative standard deviation (RSD), but that of LQC is not supposed to exceed $\pm 20 \%$ (US DHHS, FDA, CDER, 2001) [12].

\subsubsection{Stability}

\subsubsection{Short-term stability}

To test for the short term stability of the analytes, three quality control levels were left for 8 hours on bench top at room temperature (bench-top stability). This was done in triplicates.

\subsubsection{Freeze and thaw stability}

Three freeze and thaw cycles were applied to test for the analytes' stability. The general procedure mentioned above was applied for the analysis. The same criteria of data acceptance mentioned under precision apply here.

\subsubsection{Stock solution stability}

The stability of MOX, MOXT, and I.S stock solutions was performed by comparison of results from a solution kept for about 60 days at $4{ }^{\circ} \mathrm{C}$ and from a solution that was extemporaneously prepared. For this purpose, three replicates of each analyte were prepared from each stock solution and injected in the LC-MS/MS system. The same test was performed with the stock solutions of I.S. Results were compared to freshly prepared solutions at corresponding concentration. The samples qualified the test if the deviation was within $\pm 15 \%$.

\section{Results and discussion}

\subsection{Method development}

\subsubsection{Mass spectrometry}

Both positive and negative ion modes were tried for the simultaneous determination of the mixture by using only one internal standard. The Positive ion mode was found to be the most suitable for the LC-tandem mass multiple reaction monitoring (MRM) analyses. Parent ion of each analyte and IS $[\mathrm{M}+\mathrm{H}]^{+}$in the first MS was used to give the most intense product ion peak in MS3 where it was used for the quantitative measurement.

The parent ion of the protonated MOX and MOXT $(\mathrm{m} / \mathrm{z}$, $499.4)$ and $(m / z, 471)$ formed the most intense daughter ion peak at 234.2 and $m / z 206$, respectively. Also, the protonated IS (BENZ, $m / z$ 425.2) formed the most intense daughter ion peak at $m / z$ 351.2, Figure 2.

\subsubsection{Chromatographic conditions}

Different ratios of acetonitrile and buffer were tested for optimum resolution in a reasonable run time and acceptable peak shape. The most satisfactory mobile phase ratio was found to be $0.1 \%$ formic acid and acetonitrile $(30: 70, v: v)$. Two types of stationary phases C8 and C18 were investigated for the optimum resolution of the analytes peaks, however the more hydrophobic sunfire C18 was found to be more superior in separating analytes peaks in a reasonable run time.

\subsubsection{Simple protein precipitation}

Simple protein precipitation was used to obtain samples free from endogenous interferents, which are essential for increasing recovery and minimizing matrix effects in LCtandem mass spectrometry. Different precipitating solvents, like methanol, and acetonitrile were tried and tested for removing interferents and obtaining clean plasma samples leading to acceptable matrix effect and recoveries. Acetonitrile proved to be the most suitable, so it was used in the protein precipitation step.

\subsubsection{Selection of internal standard}

Internal standard (IS) is used to compensate for the analytes during any step of the analysis. Also, matrix effect could be minimized by choosing suitable IS. Several compounds were investigated, such as torasemid, gliclazide, and BENZ, and finally BENZ was found to be the most suitable IS.

\subsection{Method validation}

\subsubsection{Selectivity}

To test for the method selectivity, blank plasma samples from six different sources were analyzed to be sure that the endogenous plasma constituents show no interference at the peak region of the studied analytes and the IS. The proposed method showed no interference at the $\mathrm{m} / \mathrm{z}$ ratio of the analytes and IS, Figure 3-5.

\subsubsection{Lower limit of the quantitation (LLOQ)}

The LLOQ was defined as the lowest concentration on the calibration curves with acceptable precision and recovery. 
Table 1. The recovery and matrix effect of moexipril, moexiprilat, and IS $(n=3)$.

\begin{tabular}{|c|c|c|c|c|c|}
\hline \multirow[t]{2}{*}{ Analyte } & \multirow[t]{2}{*}{$C(\mathrm{ng} / \mathrm{mL})$} & \multicolumn{2}{|c|}{ Recovery (\%) } & \multicolumn{2}{|c|}{ Matrix effect (\%) } \\
\hline & & $\mathrm{x} \pm \mathrm{SD}$ & RSD \% & $\mathrm{x} \pm \mathrm{SD}$ & RSD \% \\
\hline \multirow[t]{3}{*}{ Moexipril } & 15 & $84.6 \pm 3.87$ & 4.57 & $99.7 \pm 2.45$ & 2.46 \\
\hline & 50 & $83.7 \pm 5.41$ & 6.46 & $98.3 \pm 1.48$ & 1.50 \\
\hline & 180 & $84.6 \pm 5.23$ & 6.18 & $98.7 \pm 1.62$ & 1.64 \\
\hline \multirow[t]{3}{*}{ Moexiprilat } & 3 & $86.5 \pm 4.84$ & 5.60 & $98.9 \pm 2.16$ & 2.18 \\
\hline & 30 & $85.1 \pm 8.64$ & 10.15 & $99.5 \pm 3.12$ & 3.14 \\
\hline & 100 & $85.5 \pm 2.47$ & 2.89 & $99.4 \pm 1.57$ & 1.58 \\
\hline IS & 10 & $87.3 \pm 4.57$ & 5.23 & $99.7 \pm 2.47$ & 2.48 \\
\hline
\end{tabular}
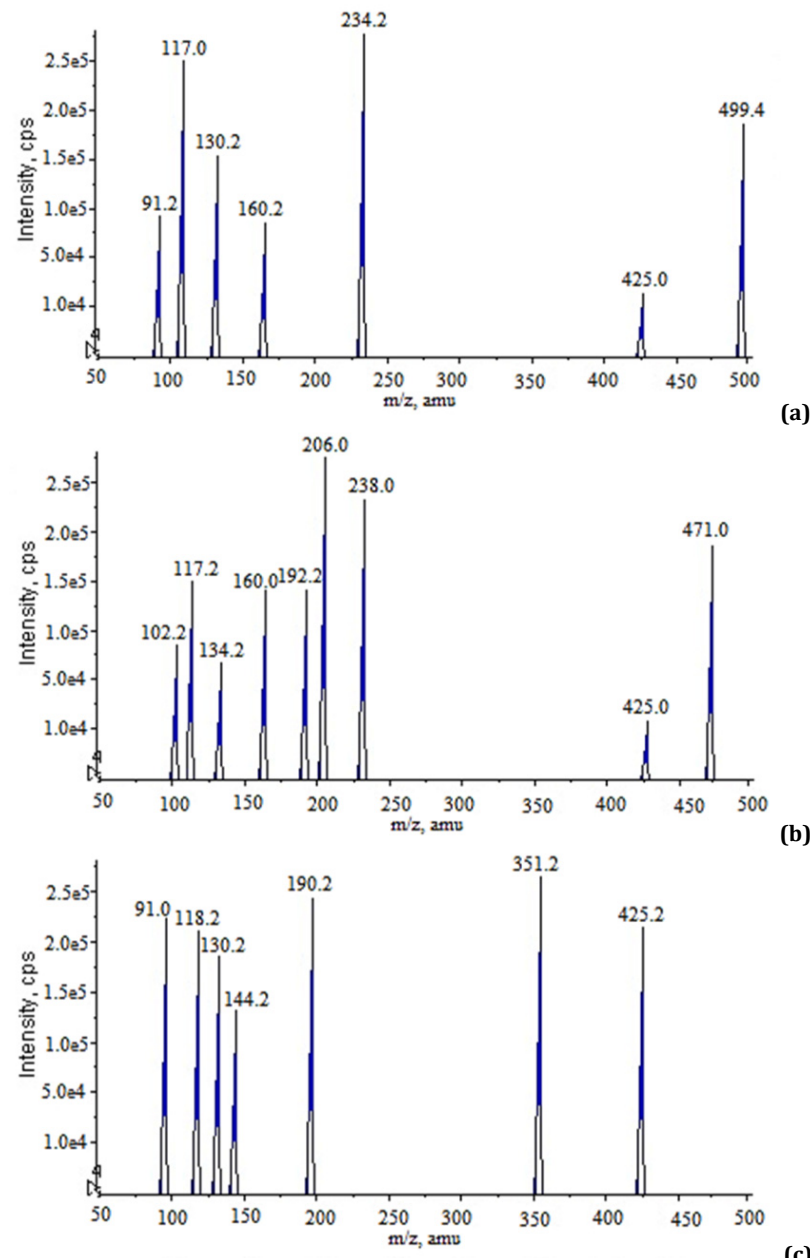

(b)

(c)

Figure 2. MS spectra for (a) Moexipril, (b) Moexiprilat, and (c) Benazepril.

The analyte response at the LLOQ should be at least five times the response of blank baseline. To test for LLOQ of the proposed method, three replicates of the spiked plasma samples were analyzed at concentrations of 0.5 and $5.0 \mathrm{ng} / \mathrm{mL}$ for MOX and MOXT, respectively. The precision and accuracy were found to be 5.09 and $102 \%$ for MOX; 0.97 and $104 \%$ for MOXT, respectively.

\subsubsection{Recovery and matrix effect}

Different precipitating solvents were tried to obtain clean samples, minimize matrix effect, and increase recovery \%. Acetonitrile proved to be the most suitable one for extraction. The recoveries and matrix effects of MOX, MOXT, and BENZ (IS) are shown in Table 1 . Where three quality control levels were tested in triplicates.

\subsubsection{Linearity}

The two analytes showed linear response where the correlation coefficients $\left(r^{2}\right)$ were all $>0.998$. The equation of each calibration curve was: $\mathrm{y}=0.0068 \mathrm{X}-0.0072\left(r^{2}=0.9981, \mathrm{n}\right.$ $=3)$ for MOX and $\mathrm{y}=0.6098 \mathrm{x}-0.135\left(r^{2}=0.9988, \mathrm{n}=3\right)$ for MOXT.

\subsubsection{Precision and accuracy}

Intra- and inter-day precision and accuracy data for plasma samples of the two analytes are shown in Table 2. The data showed acceptable results for both precision and accuracy.

\subsubsection{Stability studies}


Table 2. The intra-day and inter-day precisions and accuracy of moexipril and moexiprilat in plasma $(\mathrm{n}=3)$.

\begin{tabular}{|c|c|c|c|c|c|c|c|}
\hline \multirow[t]{2}{*}{ Analyte } & \multirow[t]{2}{*}{$\mathrm{C}(\mathrm{ng} / \mathrm{mL})$} & \multicolumn{3}{|l|}{ Intra-day } & \multicolumn{3}{|l|}{ Inter-day } \\
\hline & & $\mathrm{x} \pm \mathrm{SD}$ & Accuracy \% & RSD \% & $\mathrm{x} \pm \mathrm{SD}$ & Accuracy \% & RSD \% \\
\hline \multirow{3}{*}{ Moexipril } & 15 & $14.56 \pm 1.41$ & 97.1 & 9.68 & $14.78 \pm 2.14$ & 98.5 & 14.48 \\
\hline & 50 & $51.23 \pm 0.57$ & 102.5 & 1.11 & $48.89 \pm 1.87$ & 97.8 & 3.82 \\
\hline & 100 & $98.63 \pm 1.37$ & 98.6 & 1.39 & $98.32 \pm 0.25$ & 98.3 & 0.25 \\
\hline \multirow[t]{3}{*}{ Moexiprilat } & 5 & $4.870 \pm 0.41$ & 97.4 & 8.42 & $4.840 \pm 0.23$ & 96.8 & 4.75 \\
\hline & 30 & $29.47 \pm 1.25$ & 98.2 & 4.24 & $31.26 \pm 0.54$ & 104.2 & 1.73 \\
\hline & 100 & $99.54 \pm 0.64$ & 99.5 & 0.64 & $99.78 \pm 2.54$ & 99.8 & 2.55 \\
\hline
\end{tabular}

Table 3. Stability data of moexipril and moexiprilat in human plasma at various conditions $(n=3)$.

\begin{tabular}{|c|c|c|c|c|}
\hline Analyte & C (ng/mL) & & Bench top (8 h) & Three freeze-thaw \\
\hline Moexipril & $\begin{array}{l}15 \\
50 \\
100\end{array}$ & $\begin{array}{l}\mathrm{x} \pm \mathrm{SD} \\
\text { Accuracy \% } \\
\mathrm{x} \pm \mathrm{SD} \\
\text { Accuracy \% } \\
\mathrm{x} \pm \mathrm{SD} \\
\text { Accuracy \% }\end{array}$ & $\begin{array}{l}14.98 \pm 0.43 \\
99.87 \\
50.56 \pm 0.48 \\
101.12 \\
100.69 \pm 1.24 \\
100.69\end{array}$ & $\begin{array}{l}14.21 \pm 3.14 \\
94.73 \\
48.87 \pm 2.87 \\
97.74 \\
101.24 \pm 3.04 \\
101.24\end{array}$ \\
\hline Moexiprilat & $\begin{array}{l}5 \\
30 \\
100\end{array}$ & $\begin{array}{l}\mathrm{x} \pm \mathrm{SD} \\
\text { Accuracy } \% \\
\mathrm{x} \pm \mathrm{SD} \\
\text { Accuracy } \% \\
\mathrm{x} \pm \text { SD } \\
\text { Accuracy } \%\end{array}$ & $\begin{array}{l}5.08 \pm 1.12 \\
101.60 \\
30.87 \pm 0.76 \\
102.90 \\
99.78 \pm 1.42 \\
99.78\end{array}$ & $\begin{array}{l}5.19 \pm 2.47 \\
103.80 \\
31.65 \pm 2.41 \\
105.50 \\
98.78 \pm 0.58 \\
98.78\end{array}$ \\
\hline
\end{tabular}

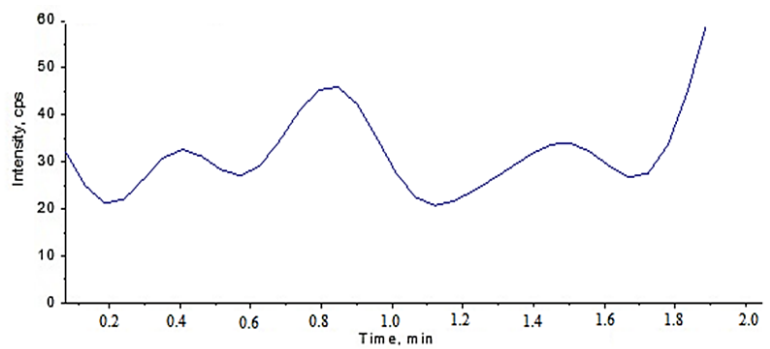

(a)

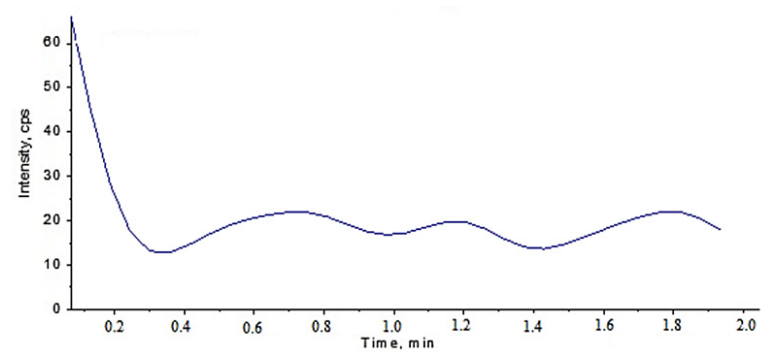

(b)

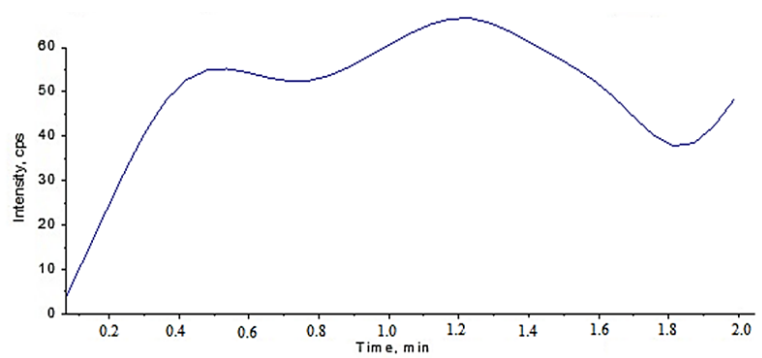

(c)

Figure 3. Blank human plasma showing no interference, a) Moexipril, (b) Moexiprilat, and (c) Benazepril.

\subsubsection{Short term stability}

Bench Top stability was checked for each analyte by leaving the spiked human plasma for 8 hours on bench-top. The concentration of the analytes never falls outside the accepted range as seen in Table 3.
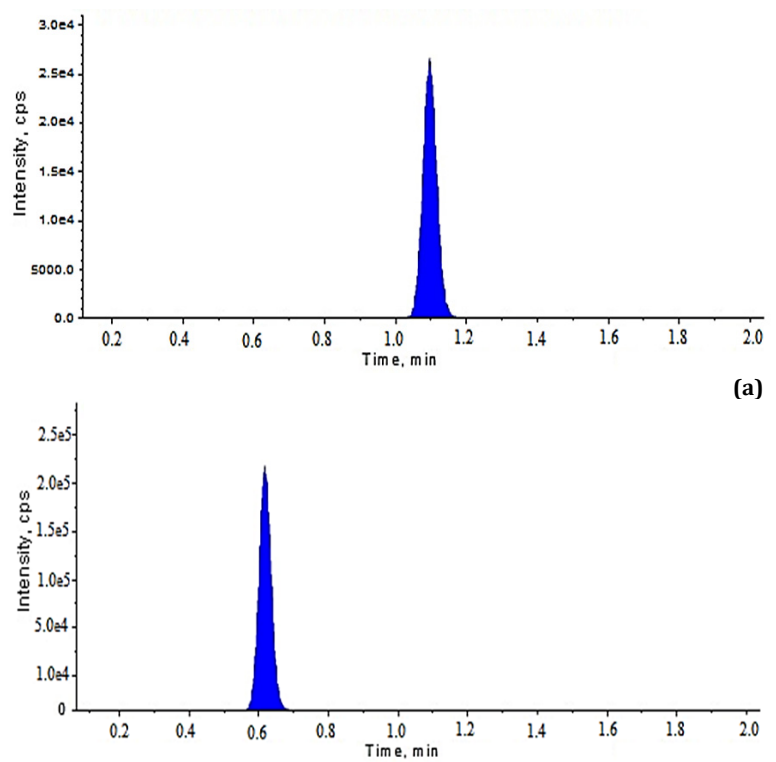

(b)

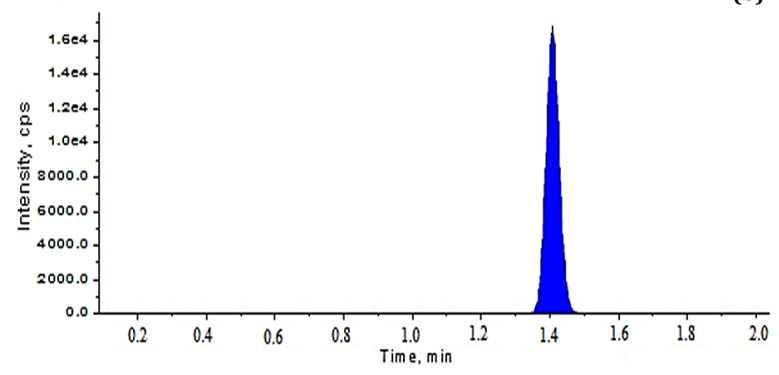

(c)

Figure 4. MRM chromatograms of moexipril (a), moexiprilat (b), and benazepril (c).

\subsubsection{Freeze and thaw stability}

The stability of the analytes in human plasma was investigated under the conditions recommended by the FDA [12]. So, freeze-thaw stability was assessed with three sets of stability control samples after three freeze-thaw cycles and during storage at $-80^{\circ} \mathrm{C}$ up to 30 days (Table 3 ). 
Table 4. Statistical comparison for the results obtained by the proposed method and the reported method [4] for the analysis of Moexipril in bulk powder.

\begin{tabular}{lllllllll} 
Method & Drug & Mean & S.D. & RSD\% & N & Variance & Student's t test (2.23) $^{\text {a }}$ & F test (5.05) a \\
\hline LC/MS & MOX & 99.32 & 2.77 & 2.788 & 6 & 7.672 & 0.258 \\
Reported method [1] b & MOX & 99.24 & 2.12 & 2.136 & 6 & 4.562 & &
\end{tabular}

$\begin{array}{llllll}\text { Reported method [1] b } & \text { MOX } & 99.24 & 2.12 & 2.136 & 6\end{array}$

b Separation was achieved on Luna C18 column $(250 \times 4.6 \mathrm{~mm}$ I.D., 5 um, acetonitrile- $20 \mathrm{mM}$ phosphate buffer $(\mathrm{pH}=4.0)(50: 50, v: v)$ at a flow rate of $1 \mathrm{~mL} / \mathrm{min}$, and UV detection at $212 \mathrm{~nm}$.

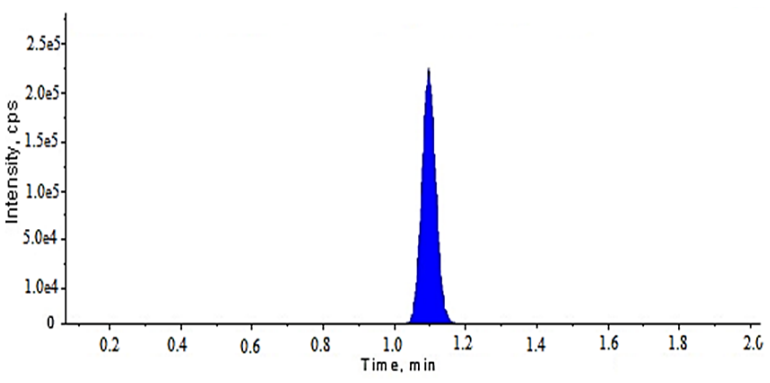

(a)

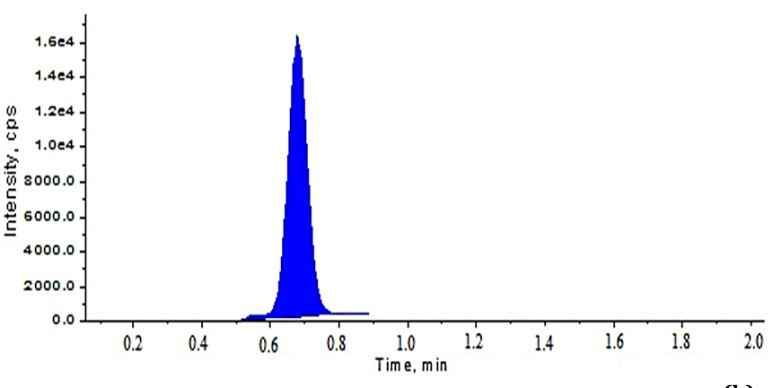

(b)

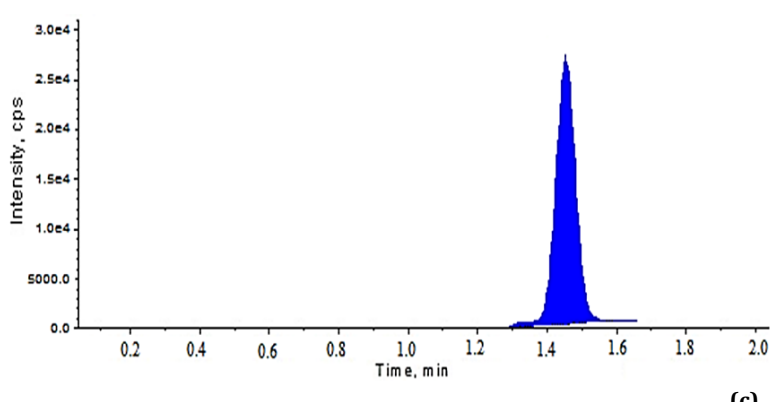

(c)

Figure 5. MRM chromatograms of moexipril (a), moexiprilat (b), and benazepril (c) in spiked human plasma.

\subsubsection{Stock solution stability}

The stability of the MOX, MOXT, and I.S. stock solutions was performed by comparison of results from a solution kept for about 60 days at $4{ }^{\circ} \mathrm{C}$ and from a solution that was extemporaneously prepared. For this purpose, three replicates of each analyte were prepared from each stock solution and injected in the LC-MS/MS system. The same test was performed with the stock solutions of I.S. Results were compared to freshly prepared solutions at corresponding concentration as shown in Table 3.

\section{Statistical analysis}

Results obtained by the proposed method for the determination of pure samples of MOX and MOXT are statistically compared to those obtained by the reported methods ${ }^{4}$. The calculated $t$ and $F$ values were found to be less than their corresponding theoretical ones confirming good accuracy and excellent precision (Table 4).

\section{Conclusions}

In the present study, both MOX and its active metabolite MOXT were determined in spiked human plasma by LCTandem mass spectrometry method using one IS. The method showed satisfactory precision and accuracy results. The run time of the developed method is too short, so it can be used in bioequivalence studies to test maximum number of samples in a short time.

\section{Acknowledgements}

The authors are grateful to Dr. Ahmed Hassan, Head of Genuine Research Centre (GRC), Cairo, Egypt. The authors gratefully acknowledge GRC laboratories for their great help to accomplish this work.

\section{References}

[1]. Moffat, A. C.; Osselton, M. D.; Widdop, B. Clarke's Analysis of Drugs and Poisons, Pharmaceutical Press, London, UK, 2005.

[2]. Brogden, R. N.; Wiseman, L. R. Drugs 1998, 55, 845-860.

[3]. Chrysant, S. G.; Chrysant, G. S. J. Clin. Pharmacol. 2004, 44, 827-836.

[4]. Stanisz, B.; Regulska, K.; Ratajczak, T. Acta Pol. Pharm. Drug Res. 2012, 69, 389-395.

[5]. Latha, Y. B.; Sankar, D. G. Int. J. Univ. Pharm. Life Sci. 2011, 1, 156-165.

[6]. Elshanawane, A. A.; Mostafa, S. M.; Elgawish, M. S. Chromatographia 2008, 67, 567-573.

[7]. Pandey, R.; Patil, P. O.; Bari, S. B.; Dhumal, D. M. Asian J. Biochem Pharm. Res. 2012, 2, 342-347.

[8]. Abd El Kawy, M.; El Gindy, A. E.; Hegazy, M.; Shokry, E. S. J. Appl. Sci. Res. 2010, 6, 918-926.

[9]. Hammes, W.; Hammes, B.; Büchsler, U.; Paar, F.; Bökens, H. Chromatogr. B: Anal. Technol. Biomed. Life Sci. 1995, 670, 81-89.

[10]. Koti, J.; Hada, V.; Petroianu, G.; Hasan, M. Y.; Tekes, K.; Szücs, Z.; Kalasz, H. J. Chromatogr. Sci. 2006, 44, 214-218.

[11]. Karra, V. K.; Mullangi, R.; Pilli, N. R.; Inamadugu, J. K.; Ravi, V. B. Seshagiri, J. V. Biomed. Chromatogr. 2012, 26, 1552-1558.

[12]. Guidance for Industry, Bioanalytical Method Validation, US Department of Health and Human Services, Food and Drug Administration, Center for Drug Evaluation and Research (CDER) Center for Veterinary Medicine (CVM), USA, 2001. 